\title{
Nifedipine vs Placebo for Treatment of Chronic Chilblains: A Randomized Controlled Trial
}

Ibo H. Souwer, $M D^{1}$

Jacobus H. J. Bor, BSc (Matb) ${ }^{2}$

Paul Smits, $M D, P b D^{3}$

Antoine L. M. Lagro-Janssen, MD, $\mathrm{PbD}{ }^{1}$

'Department of Primary and Community Care, Unit Gender and Women's Health, Radboud University Medical Center, Nijmegen, The Netherlands

${ }^{2}$ Department of Primary and Community Care, Radboud University Medical Center, Nijmegen, The Netherlands

${ }^{3}$ Department of Pharmacology and Toxicology, Radboud University Medical Center, Nijmegen, The Netherlands

Conflicts of interest: authors report none.

\section{CORRESPONDING AUTHOR}

Ibo H. Souwer, MD

Radboud University Medical Center Unit Gender and Women's Health

Department of Primary and Community Care

Internal Post Code 118

PO Box 9101

6500 HB Nijmegen

The Netherlands

i.souwer@wxs.nl

\begin{abstract}
PURPOSE Nifedipine is commonly prescribed for the treatment of chilblains (pernio, perniosis) on the basis of observational studies and a single small, older clinical trial. We aimed to confirm the proposed superiority of oral nifedipine $60 \mathrm{mg}$ per day over placebo for treatment of chronic chilblains in primary care.
\end{abstract}

METHODS We performed a randomized, placebo-controlled, double-blind, crossover trial, closely following the design of the older trial. A total of 32 patients with chronic chilblains were randomly assigned to nifedipine $(30 \mathrm{mg}$ controlled release twice a day) or placebo. The primary outcome was patient-reported complaints; the secondary outcome was patient-reported disability. Both were assessed from daily ratings on $100-\mathrm{mm}$ visual analogue scales recorded in a diary. We took ambient temperatures into account and checked for a carry-over effect, and monitored for adverse effects.

RESULTS After 6 weeks of treatment, mean scores on the visual analogue scale on complaints showed a nonsignificant difference of $1.84 \mathrm{~mm}(95 \% \mathrm{Cl},-6.67$ to $2.99 \mathrm{~mm})$ in favor of nifedipine $(P=.44)$. Mean scores on the visual analogue scale on disability showed a nonsignificant difference of $0.56 \mathrm{~mm}(95 \% \mathrm{Cl},-2.97$ to $4.09 \mathrm{~mm})$ in favor of placebo $(P=.75)$. There was no carry-over effect of prior study treatment. Nifedipine was associated with significantly lower systolic blood pressure and a significantly higher incidence of edema.

CONCLUSIONS In our study, nifedipine was not superior to placebo for treating chronic chilblains. These findings contrast with those of the older study and do not support routine use of nifedipine for this condition.

Ann Fam Med 2016;14:453-459. doi: 10.1370/afm.1966.

\section{INTRODUCTION}

hilblains (pernio, perniosis) are cold-induced, painful or itching lesions on the fingers, feet, ears, or thighs. The condition occurs throughout the world during the winter months when daily mean temperatures drop below the range of $12^{\circ} \mathrm{C}$ to $15^{\circ} \mathrm{C} .{ }^{1}$ The prevalence in the Netherlands as reported by the Netherlands Institute for Health Services Research (NIVEL) varies between 0.9 per 1,000 and 1.7 per 1,000 depending on year-to-year variation and coding issues. The condition is more common among women than men, with respective prevalences of 0.9 to 2.1 per 1,000 vs 0.6 to 1.2 per 1,000 (written information provided by NIVEL).

Patients with chilblains report serious restrictions in daily life and feel an urgent need for effective treatment. ${ }^{2}$ A review of the literature through March 15, 2016 revealed evidence that vitamin $D_{3}$, corticosteroidcontaining cream, nifedipine, and pentoxyfylline, among a wide range of other therapies, are used to treat symptoms of chronic chilblains. ${ }^{3,4}$ In an earlier study, we found that vitamin $\mathrm{D}_{3}$ was not superior to placebo, however. ${ }^{5}$ Five studies evaluating the effectiveness of nifedipine in patients with chilblains have been published and have concluded that the drug is an effective treatment. These studies included only 1 randomized controlled trial, having 10 patients and conducted in 1989, compared 
nifedipine with placebo. ${ }^{6}$ The others-a pilot case study with 10 patients, a case series with 34 patients, a randomized trial comparing diltiazem with nifedipine in 34 patients, and a study comparing nifedipine with topical minoxidil in 62 patients-were not placebo controlled. ${ }^{6-8}$

Physicians and patients are commonly advised to consider the prescription of nifedipine for the treatment of chronic chilblains. ${ }^{9-13}$ This advice finds support in a proposed disease mechanism for chilblains (ie, cold-induced vasospasm ${ }^{9,14,15}$ ) and in the results of the 5 studies previously described. ${ }^{6-8}$ Current discussion in the field regarding the reliability and reproducibility of these studies has called into question the soundness of the basis for the advice, however. ${ }^{16}$

We undertook a trial to confirm the proposed superiority of oral administration of nifedipine $60 \mathrm{mg}$ per day compared with placebo for the treatment of chronic chilblains in a primary care setting.

\section{METHODS}

\section{Trial Design}

Following the methodology of the original study by Rustin et al, ${ }^{6}$ we conducted a 13 -week randomized, double-blind, placebo-controlled, cross-over trial. ${ }^{6} \mathrm{~A}$ washout period was not incorporated in the design for 3 reasons. First, the original trial did not include a washout period. Second, for obvious reasons, the study had to be completed during the winter months; a washout period would have resulted in too long a research period per patient and problems with higher ambient temperatures in spring. Third, the exact mechanism of the proposed effect of nifedipine is unclear, so the necessary duration of a washout period is uncertain. Instead of using a washout period, we sampled the last week of every 6 -week treatment phase and checked for a possible carry-over effect.

\section{Participants}

The study population consisted of consecutively enrolled patients with chronic chilblains during the winters of 2010 to 2012. Patients volunteered after being informed of the trial by their primary care physician during consultation.

Patients were eligible for the trial if they were aged 18 years or older and reported symptoms of chronic chilblains that had lasted at least 3 weeks. The diagnosis was confirmed by an author (I.H.S.) based on commonly used diagnostic criteria: symptoms emerging in the winter months with itching and/or painful purpleblue discolored lesions in any of several locations (fingers, toes, feet, or lateral thigh) without a history of persistence into the summer months. ${ }^{1,9}$ Swelling and ulceration, and reporting of earlier episodes in previous winters could also be present but were not mandatory for diagnosis. The validity of diagnosis by this author has previously been demonstrated. ${ }^{5}$

We excluded patients who had a known rheumatologic disorder, were already using nifedipine or another calcium channel blocker, were pregnant or lactating, or had contraindications to use of nifedipine.

Our sample size calculation was based on the following premises related to the visual analogue scale (VAS) used for the trial's primary outcome. Specifically, in an earlier study, ${ }^{5}$ we observed a baseline visual analogue scale on complaints (VOC) score of $27.97 \mathrm{~mm}$ (SD 18.82) in a similar population. We used an estimate of 0.5 for the correlation between 2 scores from the same patient on 2 occasions. ${ }^{5}$ We considered the treatment effect to be clinically relevant if patients experienced a decrease in the VOC score of at least $10 \mathrm{~mm}$.

On the basis of use of a $t$ test for the difference between 2 dependent means, 1 -tail testing, an $\alpha$ of 0.05 , and a $\beta$ of 0.10 (power of $90 \%$ ), we calculated that we would need a minimum of 32 participants for the trial.

\section{Procedures}

The intervention consisted of oral administration of 30 mg nifedipine controlled release once a day for 2 weeks followed by $30 \mathrm{mg}$ nifedipine twice a day for another 4 weeks. The research medication was produced and certified under project number AKF 1720 by the Department of Pharmacy and Clinical Pharmacology, Radboud University Medical Center, Nijmegen, The Netherlands.

The pharmacy that produced the research medication used block randomization with a block size of 10 to assign patients to $2 \mathrm{arms}$ that differed with respect to the order of treatments: placebo first or nifedipine first. Both research personnel and patients were blinded to arm assignment. Blinding was ensured by use of indistinguishable capsules for active medication and inactive placebo. Consecutively enrolled patients received medication sets with consecutive therapy numbers. The pharmacy released the randomization key only after the last patient had left the study.

In the placebo-first arm, patients received no medication for 1 week to collect baseline data (phase 0 ), followed by use of placebo once a day for 2 weeks, followed by use of placebo twice a day for 4 weeks (phase 1), followed by nifedipine $30 \mathrm{mg}$ controlled release once a day for 2 weeks, followed by nifedipine $30 \mathrm{mg}$ controlled release twice a day for 4 weeks (phase 2). In the nifedipine-first arm, patients received no medication for 1 week to collect baseline data (phase 0), followed by nifedipine $30 \mathrm{mg}$ controlled release once a day for 2 weeks, followed by nifedipine $30 \mathrm{mg}$ controlled release 
twice a day for 4 weeks (phase 1), followed by use of placebo once a day for 2 weeks, followed by use of placebo twice a day for 4 weeks (phase 2).

Each day, we documented the mean ambient temperature provided by the Royal Netherlands Meteorological Institute. Patients used a diary to score the presence and severity of itch, pain, and disability using the VAS daily throughout the full research period, as described below. Investigators had 6 face-to-face contacts with patients: at intake and at the end of weeks $1,3,7,9$, and 13. During these contacts, the investigators checked diaries for completeness, assessed therapy compliance by counting capsules, and documented remaining lesions.

The Dutch Competent Authority (NL31484.091.10 $\mathrm{BI}$ ) and the Medical Research Ethics Committee CMO Arnhem-Nijmegen (CMO dossier number 2010/240) granted permission for this study.

\section{Outcomes}

The trial's primary and secondary outcomes were patient-reported complaints (symptoms) and disability, respectively, assessed with VAS having 100 mm ranges. Patients rated these outcomes daily and recorded their ratings in diaries.

The primary outcome was the difference in score on the VOC between nifedipine and placebo after 6 weeks of treatment. Patients rated pain and itch separately; we used the higher of these 2 scores at the time of reporting. The VOC score was calculated as the mean value for the last 7 days of the 6 -week treatment period. Higher scores indicated greater pain or itch.

The secondary outcome was the difference in score on the visual analogue scale on disability (VOD) between nifedipine and placebo after 6 weeks of treatment. For this outcome, patients rated their ability to function normally in daily life. The VOD score was also calculated as the mean value of the last 7 days of the treatment period. Higher scores indicated greater disability.

To follow the design of the original study ${ }^{6}$ as closely as possible, investigators assessed the chilblain lesions during face-to-face contacts and rated redness, purpleness, edema, and ulceration on 100-mm VAS. We also monitored for adverse effects - unfavorable changes in blood pressure reading and in scores for headache, dizziness, and peripheral edema on 100-mm VAS — at each of these contacts.

\section{Statistical Analysis}

We used a modified intention-to-treat analysis, including data only of patients who began the study. We performed analysis of the primary and secondary patientreported outcomes using the 2-stage model originally proposed by Grizzle ${ }^{17}$ and more recently reviewed, ${ }^{18}$ correcting for temperature changes during the research period for each patient with a mixed effects model (Grizzle model using the mixed procedure with random effect, SAS PROC MIXED, SAS version 9.2; SAS Institute Inc). Investigator-assessed outcomes and adverse effects were analyzed using 2 -sample paired $t$ tests.

\section{RESULTS}

\section{Patient Characteristics}

The procedure used to assess and enroll patients is shown in Figure 1. Data for 32 patients (18 women and 14 men) were available for analysis, and their baseline characteristics are shown in Table 1 . The patients had a mean age of 53 years (SD 16.1). The mean duration of symptoms at intake was 6.5 weeks (SD 3.6). At baseline, the mean score on the VOC scale was $24.92 \mathrm{~mm}(95 \%$

\section{Figure 1. Flowchart of patients in the trial.}

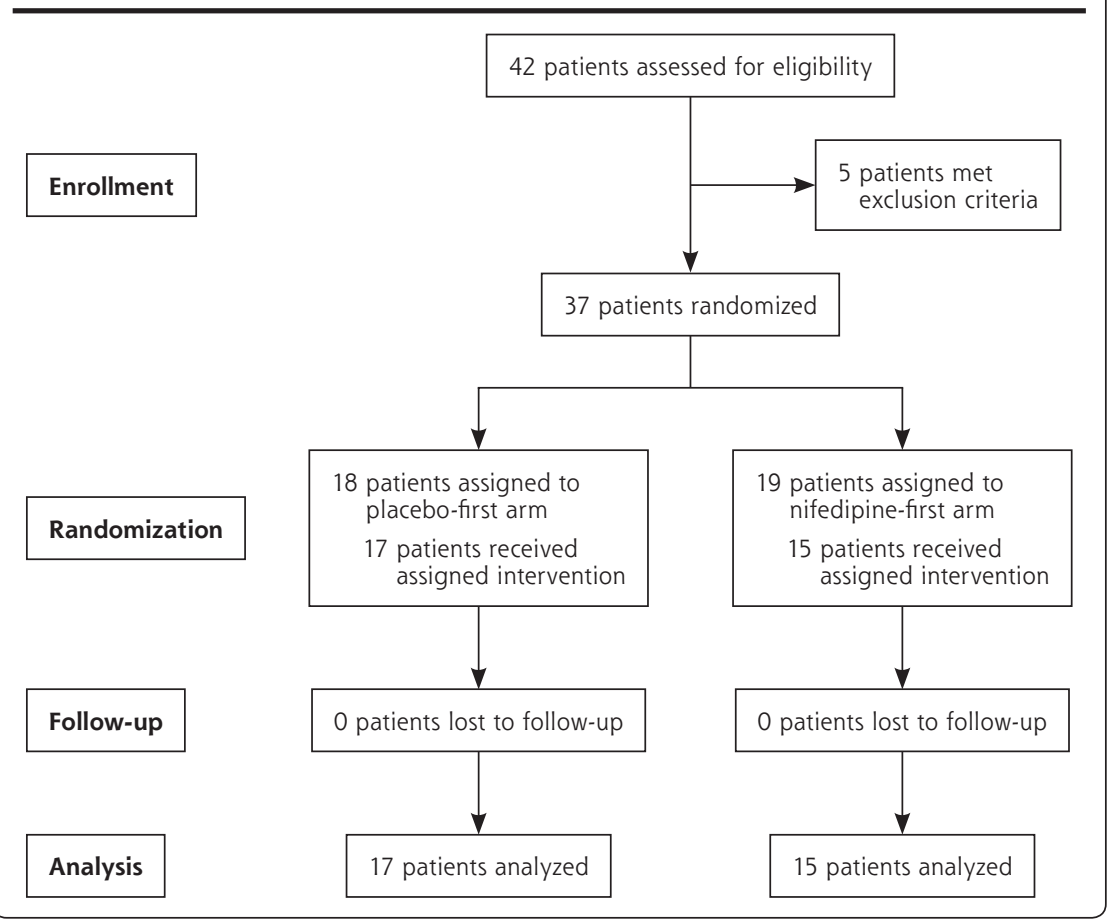


CI, 21.70-28.13) and the mean score on the VOD scale was $16.11 \mathrm{~mm}$ (95\% CI, 13.09-19.13). Eleven patients had possibly relevant comorbidities, 6 smoked, and 9 used potentially relevant drugs.

Our capsule counts indicated that patients did not take 502 capsules $(11 \%)$ of the 4,480 they had been assigned to take. Diaries were conscientiously completed. No face-to-face contacts were missed.

We did not find any missing data for the patientreported primary and secondary outcomes or for adverse effects. One assessment for our investigatorassessed outcomes was missing, representing 4 VAS scores out of 384 to be analyzed ${ }_{i}$ we did not replace these missing data.

\section{Primary and Secondary Outcomes}

Figure 2 shows the plots of mean VOC and VOD scores per week, not corrected for temperature, in each arm and study phase.

The mean VOC score at 6 weeks of treatment was $11.44 \mathrm{~mm}(95 \% \mathrm{CI}, 6.12-16.75 \mathrm{~mm})$ with nifedipine treatment and $13.28 \mathrm{~mm}(95 \% \mathrm{CI}, 7.96-18.59 \mathrm{~mm})$ with placebo treatment (Table 2). This resulted in a difference between arms of $1.84 \mathrm{~mm}(95 \% \mathrm{CI},-6.67$ to 2.99 $\mathrm{mm})$ in favor of nifedipine $(P=.44)$.

The mean VOD score at 6 weeks of treatment was $4.65 \mathrm{~mm}(95 \% \mathrm{CI}, 1.65-7.65 \mathrm{~mm})$ with nifedipine treatment and $4.09 \mathrm{~mm}(95 \% \mathrm{CI}, 10.9-7.09 \mathrm{~mm})$ with placebo treatment. This resulted in a difference between arms of $0.56 \mathrm{~mm}(95 \% \mathrm{CI},-2.97$ to $4.09 \mathrm{~mm})$ in favor of placebo $(P=.75)$.

\section{Carry-Over Effect}

Results of analyses assessing any carry-over effect on the primary outcome are shown in Table 2 . The mean VOC score at 6 weeks of treatment was $14.07 \mathrm{~mm}$ (95\% CI, 7.16-20.98 $\mathrm{mm}$ ) in the arm given placebo first and $10.46 \mathrm{~mm}(95 \% \mathrm{CI}, 4.16-17.14 \mathrm{~mm})$ in the arm given nifedipine first. This resulted in a nonsignificant difference between arms of $3.43 \mathrm{~mm}(95 \% \mathrm{CI},-6.08$ to $12.93 \mathrm{~mm})$ in favor of the nifedipine-first arm $(P=.47)$, indicating no carry-over effect.

Results of analyses assessing any carry-over effect on the secondary outcome are shown in Table 3 . The mean VOD score at 6 weeks of treatment was $4.95 \mathrm{~mm}(95 \% \mathrm{CI}, 1.40-8.50 \mathrm{~mm})$ in the placebo-first arm and $3.97 \mathrm{~mm}(95 \% \mathrm{CI}$, 0.46-7.12 mm) in the nifedipine-first arm. This resulted in a nonsignificant difference between arms of $1.17 \mathrm{~mm}(95 \% \mathrm{CI},-3.72$ to $6.05 \mathrm{~mm}$ ) in favor of the nifedipine-first arm $(P=.63)$, also indicating no carry-over effect.

\section{Investigator-Assessed Outcomes}

We found no statistically significant differences between nifedipine and placebo for investigator-assessed redness or purpleness, edema, or ulceration after 6 weeks of treatment (Table 3).

\section{Adverse Effects}

Mean systolic blood pressure was $134.5 \mathrm{~mm}$ $\mathrm{Hg}$ after 6 weeks of nifedipine use and 147.1 $\mathrm{mm} \mathrm{Hg}$ after 6 weeks of placebo use (Table 4). The mean difference was $-13.1 \mathrm{~mm} \mathrm{Hg}$ (95\% CI, -24.1 to $-2.0 \mathrm{~mm} \mathrm{Hg}$ ), which was statistically significant $(P=.02)$. The mean assessed peripheral edema score on the VAS was $12.1 \mathrm{~mm}$ after 6 weeks of nifedipine use and $2.5 \mathrm{~mm}$ after 6 weeks of placebo use. The mean difference was $9.6 \mathrm{~mm}(95 \% \mathrm{CI}$, $1.1-18.1 \mathrm{~mm}$ ), which was also statistically significant $(P=.03)$. Headache and dizziness did not differ significantly between nifedipine and placebo after 6 weeks of treatment (Table 4). 
Figure 2. Patient-reported scores for complaints (VOC) and disability VOD (not corrected for temperature) for each arm and study phase.

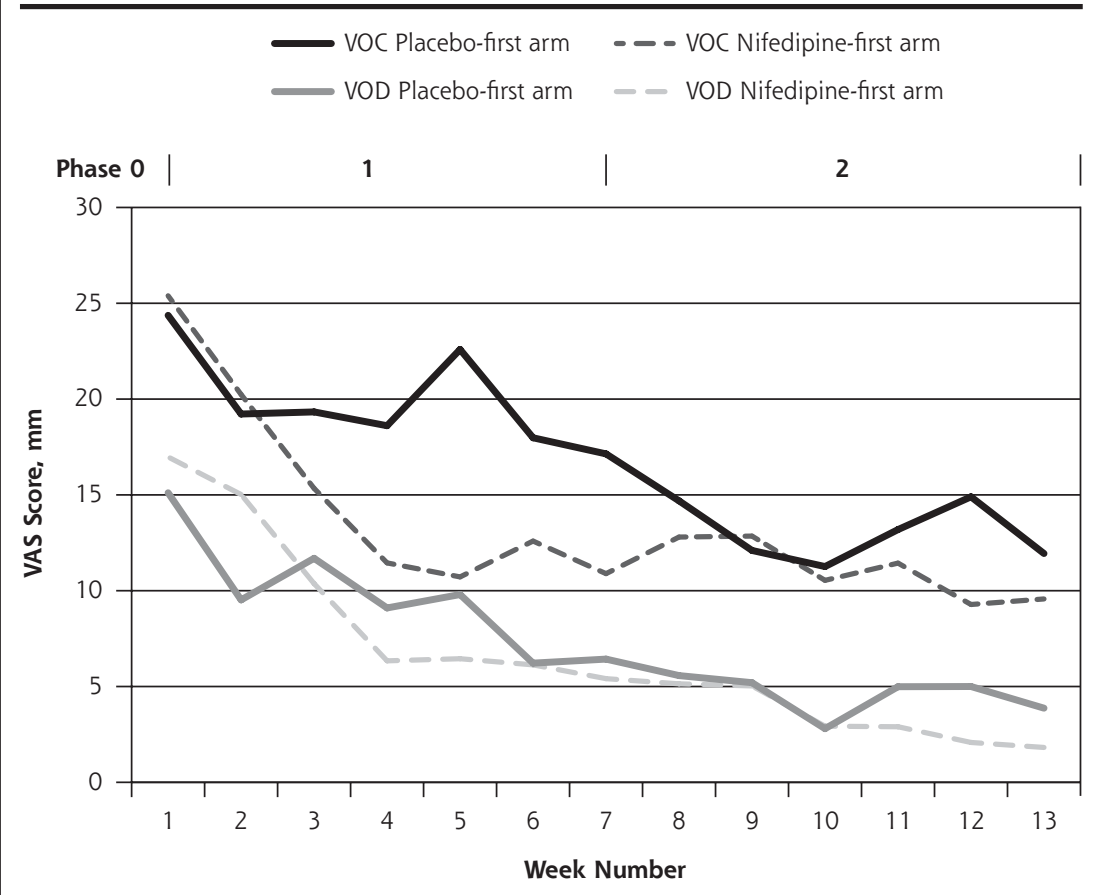

VAS = visual analogue scale; $V O C=$ visual analogue scale on complaints; $V O D=$ visual analogue scale on disability Notes: Scores measured on 100-mm scales where higher values indicate more complaints (symptoms) or greater disability. Phase 0: no-treatment baseline; phase 1: first assigned treatment; phase 2: second assigned treatment.

Table 2. Primary and Secondary Outcomes Corrected for Differences in Ambient Temperature

\begin{tabular}{|c|c|c|c|c|}
\hline \multirow[b]{2}{*}{ Outcome } & \multicolumn{2}{|c|}{ Score, $\mathrm{mm}^{\mathrm{a}}$} & \multicolumn{2}{|c|}{$\begin{array}{l}\text { Test of Fixed } \\
\text { Effects }\end{array}$} \\
\hline & Mean $(95 \% \mathrm{Cl})$ & Difference $(95 \% \mathrm{Cl})$ & F Value & $\begin{array}{l}P \text { Value } \\
(r>F)\end{array}$ \\
\hline \multicolumn{5}{|c|}{ Primary: VOC score } \\
\hline \multicolumn{5}{|l|}{ Treatment } \\
\hline Nifedipine & 11.44 (6.12 to 16.75$)$ & - & - & - \\
\hline Placebo & 13.28 (7.96 to 18.59$)$ & $-1.84(-6.67$ to 2.99$)$ & 0.61 & .44 \\
\hline \multicolumn{5}{|l|}{ Arm } \\
\hline Placebo first & 14.07 (7.16 to 20.98$)$ & - & - & - \\
\hline Nifedipine first & 10.65 (4.16 to 17.14$)$ & $3.43(-6.08$ to 12.93$)$ & 0.54 & .47 \\
\hline Temperature & - & - & 3.62 & .07 \\
\hline \multicolumn{5}{|c|}{ Secondary: VOD score } \\
\hline \multicolumn{5}{|l|}{ Treatment } \\
\hline Nifedipine & 4.65 (1.65 to 7.65$)$ & - & - & - \\
\hline Placebo & 4.09 (1.09 to 7.09$)$ & 0.56 (-2.97 to 4.09$)$ & 0.10 & .75 \\
\hline \multicolumn{5}{|l|}{ Arm } \\
\hline Placebo first & 4.95 (1.40 to 8.50$)$ & - & - & - \\
\hline Nifedipine first & 3.79 (0.46 to 7.12$)$ & $1.17(-3.72$ to 6.05$)$ & 0.24 & .63 \\
\hline Temperature & - & - & 1.63 & .21 \\
\hline
\end{tabular}

\section{DISCUSSION}

We did not find any clinically or statistically significant differences in favor of nifedipine over placebo for the treatment of chronic chilblains. The difference in patient-reported complaints (symptoms) tended to favor nifedipine, while the difference in patient-reported disability tended to favor placebo. Nifedipine was associated with a lower systolic blood pressure and a higher incidence of edema. We did not find any significant carry-over effect of prior treatment on the primary or secondary outcome. Differences between the nifedipinefirst and placebo-first arms tended to favor the former.

\section{Strengths and Limitations}

The main strength of this study is our effort to confirm the findings of the original randomized controlled trial that led to the current general advice to consider nifedipine for the treatment of chronic chilblains. No such confirmation study had previously been performed. We followed the design of the original study as closely as possible but tripled the number of patients based on our sample size calculation. Improving on the original design, we further took into account ambient temperature as a major confounder. ${ }^{3,19,20}$

We assessed primary and secondary outcomes with VAS scores for pain, itch, and disability using patient diaries. These scales are generally used and validated for this purpose. ${ }^{21-23}$

Patient compliance was good. Although $11 \%$ of assigned capsules were not taken, known adverse effects of nifedipine (lower systolic blood pressure and more edema) were still seen during nifedipine treatment. 
Table 3. Investigator-Assessed Outcomes After 6 Weeks of Treatment

\begin{tabular}{|c|c|c|c|c|}
\hline Outcome $^{a}$ & Placebo & Nifedipine & $\begin{array}{c}\text { Mean Difference } \\
(95 \% \mathrm{Cl})\end{array}$ & $\begin{array}{c}P \\
\text { Value }\end{array}$ \\
\hline Redness score, mean, mm & 17.0 & 18.3 & $1.9(-3.8$ to 7.6$)$ & .50 \\
\hline Purpleness score, mean, mm & 6.6 & 4.9 & $-1.5(-5.6$ to 2.6$)$ & .47 \\
\hline Edema score, mean, mm & 4.9 & 7.8 & $3.2(-0.5$ to 6.9$)$ & .09 \\
\hline Ulceration score, mean, $\mathrm{mm}$ & 0.0 & 0.2 & $0.2(-0.2$ to 0.6$)$ & .33 \\
\hline
\end{tabular}

${ }^{a}$ Assessed using 100-mm visual analogue scales where higher values indicate greater severity.

Table 4. Adverse Effects After 6 Weeks of Treatment

\begin{tabular}{|c|c|c|c|c|}
\hline Outcome $^{a}$ & Placebo & Nifedipine & $\begin{array}{l}\text { Mean Difference } \\
(95 \% \mathrm{Cl})\end{array}$ & $\begin{array}{c}P \\
\text { Value }\end{array}$ \\
\hline $\begin{array}{l}\text { Systolic blood pressure, } \\
\text { mean, mm Hg }\end{array}$ & 147.1 & 134.5 & $-13.1(-24.1$ to -2.01$)$ & .02 \\
\hline Headache score, mean, $\mathrm{mm}^{\mathrm{a}}$ & 2.2 & 6.9 & $4.7(-0.8$ to 10.3$)$ & .09 \\
\hline Dizziness score, mean, mma & 1.6 & 4.7 & $3.1(-1.0$ to 7.2$)$ & .13 \\
\hline $\begin{array}{l}\text { Peripheral edema score, } \\
\text { mean, } \mathrm{mm}^{\mathrm{a}}\end{array}$ & 2.5 & 12.1 & $9.6(1.1$ to 18.1$)$ & .03 \\
\hline
\end{tabular}

changing habits during the study. Nevertheless, we consider it to be unlikely because nearly all patients with chilblains have already tried almost everything to relieve their symptoms. ${ }^{2}$ In our opinion, the reduction of symptoms during placebo treatment likely reflects both a placebo effect and the natural course of the disease.

\section{Comparison With Existing Literature}

Our findings contrast with those of the original randomized controlled trial by Rustin et al. ${ }^{6}$ We did not reproduce their clear positive effect of nifedipine compared with placebo either in patient diary data or in our investigator assessment of the chilblains. Our findings are also

Patients conscientiously completed their diaries and did not miss any face-to-face contacts.

Because of the recruitment method used for our trial, we can generalize our findings to patients with idiopathic chronic chilblains in general practice.

Almost one-half of our participants reported having Raynaud phenomenon as a comorbidity (Table 1). This high figure may suggest some sort of relationship between chronic chilblains and Raynaud phenomenon. We did not exclude participants who had this condition because it can be easily distinguished from chronic chilblains. ${ }^{24-26}$ It is unlikely that the high prevalence of Raynaud phenomenon affected our results as placebo-controlled trials indicate that nifedipine and other calcium channel blockers are effective for treating that condition. ${ }^{27}$

We found a remarkable reduction of chilblains symptoms during placebo treatment that may have several explanations. First, the placebo effect may have been responsible. ${ }^{28}$ Second, almost all studies on chilblains report that $60 \%$ to $70 \%$ of the patients experience an improvement. ${ }^{3}$ None of these studies thoroughly corrected for the influence of exposure to cold and other confounders, however. Third, we did not collect information about therapy received for previous episodes, but in our opinion, prior therapy is unlikely to have influenced our results. Last, we did not ask our patients not to change their habits during the study, which raises the possibility of a Hawthorne effect. ${ }^{29}$ We are unable to exclude such an effect caused by patients' own efforts to alleviate their symptoms by at odds with the results of the other, non-placebocontrolled studies on the use of nifedipine to treat chronic chilblains. ${ }^{6-8}$

\section{Implications for Practice}

Our randomized controlled trial failed to confirm effectiveness of nifedipine for the treatment of chronic chilblains in general practice and showed evidence that its use in this context may cause harm. These findings underscore the importance of rigorous evaluation of treatments, with adequate numbers of patients and control for potential confounders, before widespread adoption. Current advice to prescribe nifedipine for chilblains should be revisited, and clinicians should weigh and discuss with patients evidence on the potential benefits and harms of various treatment options before making treatment decisions.

To read or post commentaries in response to this article, see it online at http://www.annfammed.org/content/14/5/453.

Key words: chilblains; therapeutics; nifedipine; randomized controlled trial; practice-based research; primary care

Submitted January 14, 2016; submitted, revised, April 8, 2016; accepted April 25, 2016.

Funding support: This work was supported by the Netherlands Organization for Health Research and Development Program Common Diseases grant number 42011006 .

Registration details: EudraCT: registration number 2009-016397-33; Netherlands Trial Register: registration number NTR 2591.

Acknowledgments: The authors are grateful for the assistance of Mrs C.M. (Rina) Siemons, research assistant. 


\section{References}

1. Souwer IH, Lagro-Janssen ALM. Chronic chilblains. BMJ. 2011;342: d2708.

2. Souwer IH, Robins LJH, Lagro-Janssen ALM. Chilblains from the patient's perspective. Eur J Gen Pract. 2007;13(3):159-160.

3. Souwer IH, Lagro-Janssen ALM. De behandeling van perniones [The treatment of perniosis. A literature study]. Huisarts Wet. 2004; 47(12):561-562.

4. Al-sudany NK. Treatment of primary perniosis with oral pentoxifylline (a double-blind placebo-controlled randomized therapeutic trial). Dermatol Ther. 2016;(2):1-6.

5. Souwer IH, Lagro-Janssen ALM. Vitamin D3 is not effective in the treatment of chronic chilblains. Int J Clin Pract. 2009;63(2):282-286.

6. Rustin MHA, Newton JA, Smith NP, Dowd PM. The treatment of chilblains with nifedipine: the results of a pilot study, a double-blind placebo-controlled randomized study and a long-term open trial. Br J Dermatol. 1989;120(2):267-275.

7. Kubais TAI, Hasan AS, Awad KM, Tawfig EM. Treatment of perniosis with oral nifedipine in comparison with topical 5\% minoxidil solution in Iraqi patients. Single blind comparative study. AL-Anbar Med J. 2010;8(1):40-46.

8. Patra AK, Das AL, Ramadasan P. Diltiazem vs. nifedipine in chilblains: a clinical trial. Indian J Dermatol Venereol Leprol. 2003;69(3):209-211.

9. Goette DK. Chilblains (perniosis). J Am Acad Dermatol. 1990;23 (2 Pt 1):257-262.

10. Almahameed A, Pinto DS. Pernio (chilblains). Curr Treat Options Cardiovasc Med. 2008;10(2):128-135.

11. Paul M, Sharma M, Littlewood S, Leach I. Minerva. BMJ. 2011;342: d3170.

12. National Organization for Rare Disorders (NORD). For Patients and Families. Perniosis. http://www.rarediseases.org/rare-diseaseinformation/rare-diseases/bylD/736/printFullReport. Accessed Jan 30, 2015.

13. Mayo Clinic. Patient Care and Health Information. Diseases and Conditions. Chilblains. Treatment. http://www.mayoclinic.org/ diseases-conditions/chilblains/basics/treatment/con-20033727. Accessed Jan 30, 2015.

14. Lewis T. Observations on some normal and injurious effects of cold upon the skin and underlying tissues: II. Chilblains and allied conditions. Br Med J. 1941;2(4223):837-839.
15. Shahi V, Wetter DA, Cappel JA, Davis MDP, Spittell PC. Vasospasm is a consistent finding in pernio (chilblains) and a possible clue to pathogenesis. Dermatology. 2015;231(3):274-279.

16. loannidis JPA. Why most published research findings are false. PLoS Med. 2005;2(8):e124.

17. Grizzle JE. The two-period change-over design and its use in clinical trials. Biometrics. 1965;21:467-480.

18. Wang SJ, Hung HM. Use of two-stage test statistic in the twoperiod crossover trials. Biometrics. 1997;53(3):1081-1091.

19. Jacob JR, Weisman MH, Rosenblatt SI, Bookstein JJ. Chronic pernio. A historical perspective of cold-induced vascular disease. Arch Intern Med. 1986;146(8):1589-1592.

20. Raza N, Sajid Mu, Suhail M, Haroon-ur-Rashid. Onset of chilblains in relation with weather conditions. J Ayub Med Coll Abbottabad. 2008;20(2):17-20.

21. Ferreira-Valente MA, Pais-Ribeiro JL, Jensen MP. Validity of four pain intensity rating scales. Pain. 2011;152(10):2399-2404.

22. Reich A, Heisig M, Phan NQ, et al. Visual analogue scale: evaluation of the instrument for the assessment of pruritus. Acta Derm Venereol. 2012;92(5):497-501.

23. Boonstra AM, Schiphorst Preuper HR, Reneman MF, Posthumus JB, Stewart RE. Reliability and validity of the visual analogue scale for disability in patients with chronic musculoskeletal pain. Int J Rehabil Res. 2008;31(2):165-169.

24. Maverakis E, Patel F, Kronenberg DG, et al. International consensus criteria for the diagnosis of Raynaud's phenomenon. J Autoimmun. 2014;48-49:60-65.

25. Block JA, Sequeira W. Raynaud's phenomenon. Lancet. 2001;357 (9273):2042-2048.

26. Wigley FM. Clinical practice. Raynaud's phenomenon. N Engl J Med. 2002;347(13):1001-1008.

27. Ennis $H$, Anderson ME, Wilkinson J, Herrick AL. Calcium channel blockers for primary Raynaud's phenomenon. [Review]. Cochrane Database Syst Rev. 2014;(1):CD002069.

28. Brody $\mathrm{H}$. The lie that heals: the ethics of giving placebos. Ann Intern Med. 1982;97(1):112-118.

29. Sedgwick P, Greenwood N. Understanding the Hawthorne effect. BMJ. 2015;351:h4672. 